\title{
Experimental Investigation of the Mechanical Failure Behavior of Coal Specimens With Water Intrusion
}

\author{
Qiangling Yao, Chuangkai Zheng*, Chuanjin Tang, Qiang Xu, Zhaohui Chong and \\ Xuehua Li
}

Key Laboratory of Deep Coal Resource Mining, Ministry of Education of China, School of Mines, China University of Mining and Technology, Xuzhou, China

OPEN ACCESS

Edited by:

Yanlin Zhao,

Hunan University of Science

and Technology, China

Reviewed by:

Mojgan Hadi Mosleh,

The University of Manchester,

United Kingdom

Zijun Feng,

Taiyuan University of Technology,

China

Qinglei Yu,

Northeastern University, China

*Correspondence:

Chuangkai Zheng

zckcumt@163.com

Specialty section:

This article was submitted to Earth and Planetary Materials, a section of the journal

Frontiers in Earth Science

Received: 19 October 2019

Accepted: 16 December 2019

Published: 14 January 2020

Citation:

Yao Q, Zheng C, Tang C, Xu Q,

Chong $Z$ and Li $X$ (2020) Experimental Investigation of the Mechanical Failure

Behavior of Coal Specimens With

Water Intrusion.

Front. Earth Sci. 7:348.

doi: 10.3389/feart.2019.00348
Mining fissures formed by coal mining can easily open bedrock and loose aquifers, and can thus cause water-rock interaction. The strength of coal and rock and their pore and fracture development characteristics are closely related to moisture content. Therefore, this paper studied the strength, porosity, fracture propagation, and failure characteristics of coal with different moisture contents. Six representative coal samples with different moisture contents of $0,3.79,6.10,9.17,11.01$, and $11.68 \%$ were prepared by non-destructive water immersion experiment, and the samples were analyzed using. Nuclear Magnetic Resonance (NMR) and uniaxial compression acoustic emission experiments. Then, the temporal and spatial variation of the moisture contents of the coal samples and the characteristics of crack propagation and failure were studied before and after water immersion. Non-destructive water immersion and NMR analysis showed that the moisture content increases exponentially with increasing water immersion time and immersion frequency. Additionally, it was shown that with increasing water immersion time and frequency, the moisture distribution within the coal samples changes from uneven to uniform, and micro-pores and meso-pores develop into larger pores with increasing water content. A coupled uniaxial compression-acoustic emission experiment showed that acoustic emissions are closely related to the macroscopic failure mode of the coal sample. With increasing sample moisture content, the degree of sample destruction and the concentration of acoustic emissions both reduced. The increase of moisture content promotes the change of the macroscopic failure mode of the coal samples from tensile failure to tensile-shear composite failure. The results of this study have important reference value for analyzing the stability of coal pillars and surrounding rock under the action of water, and especially for the design of coal pillar dam bodies in coal mines with groundwater reservoirs.

Keywords: water-rock interaction, pore fracture expansion, failure characteristics, Nuclear Magnetic Resonance, acoustic emission

\section{INTRODUCTION}

Coal mining destroys the structure and integrity of roof overburden, which changes the runoff mode of aquifers from inter-layer runoff to vertical runoff. Seepage (due to cracking) into the mined-out area of the mine can form an artificial aquifer, and determining how best to utilize this part of the mining water resource is of great importance for coal mining and sustainable 
development. Gu (2015) and Gu et al. (2016) proposed the use of coal-mine goaf to establish a groundwater reservoir to store groundwater, that is, to connect the coal pillar dam and the artificial dam and also proposed the use of the coal mine goaf as a water storage space to preserve and utilize groundwater. This approach has been promoted and applied in the Shendong mining area, Shaanxi Province, China. The stability of the coal pillar dam is essential for the safe operation of the underground reservoir. This stability can be compromised by the influence of overburden load, mining stress, and dynamic and static water pressure in the goaf. Therefore, it is especially important to study the strength, fracture propagation, and failure characteristics of coal pillars for different moisture contents.

The study of water-rock interaction can not only help to solve problems in underground engineering (Chen et al., 2015; Hashiba and Fukui, 2015), but can also help to improve the exploitation of resources in ecologically fragile areas. Heggheim et al. (2004) found that, when limestone was immersed in different concentrations of brine, the ion and limestone components of the brine were changed, and that this immersion also caused changes in the structural and mechanical properties of the limestone. Verstrynge et al. (2014) performed an experimental study of iron-bearing sandstones with different water contents, and found that the number of acoustic emissions from the rock samples was negatively correlated with water content, and that increasing water content promoted creep damage to the rock samples. Based on the analysis of water-rock interaction, $\mathrm{Hu}$ et al. (2019) explored the impact of oil shale on the groundwater environment during in situ mining, and found that oil shale mining caused the continuous pollution of groundwater. Additionally, in order to understand the interaction between the formation and the fracturing fluid during tight gas exploitation, and the consequences of this interaction, Osselin et al. (2019) analyzed water samples from 17 different production wells collected in the same area. They found that the water-rock interaction process increased the oxidation level of the fracturing fluid. Zhao Y. L. et al. (2016); Zhao et al. $(2018,2019)$ analyzed the water-rock interaction and the development process of fractured rocks from the aspects of plasticity and fracture mechanics, and their research results are instructive for this article. Furthermore, various authors have conducted loading and unloading experiments of rock samples with different moisture contents to determine the elastic modulus, peak stress, etc., of the samples (e.g., Pan et al., 2010; Yao et al., 2015; Chen et al., 2017; Daraei and Zare, 2018). These studies found that the aforementioned parameters are inversely related to the moisture content of the rock samples, while the peak strain increases with increasing moisture content.

The strength of coal and rock masses is closely related to the degree of fracture development at different stages of failure. Researchers have explored the spatial distribution of cracks in coal and rock masses by different means. Moradian et al. (2016) analyzed the degree of cracking of brittle rocks by analyzing their acoustic emissions. Zhang J. et al. (2016) used the measurement of acoustic emissions to detect the rupture process of rock samples, and found that the damage to rock samples can be predicted by the frequency of the emissions. With the advance of science and technology, Computed Tomography (CT), Nuclear Magnetic Resonance (NMR), and Mercury Intrusion are increasingly being used to study and test the microstructural characteristics of coal and rock masses (Yu et al., 2016; Zhang Y. et al., 2016; Zhao J. L. et al., 2016, Zhao Y. X. et al., 2016; Mathews et al., 2017). Additionally, acoustic emission parameters can be used to represent post-peak fissure development (Khazaei et al., 2015); however, there is still a lack of effective means of inverting the development of fissures.

Previous studies have focused on analyzing the change in coal moisture content over time and the changes in coal physical properties that is associated with this change. However, studies of the spatial dynamic characteristics, mechanical properties, and failure modes of coal under different water moisture contents are relatively rare. The water volume of a groundwater reservoir varies due to the fissuring of submerged rock and the removal of water for mining; this results in constant changes to the water level-that is, the water content of the coal pillar dam is a dynamic variable. Therefore, it is of great importance to study the effect of changes in moisture content on the mechanical properties and fracture propagation and failure characteristics of coal pillar dams. This study takes 52 coal from the Daliuta coal mine as the research object. This coal seam has a groundwater reservoir in the goaf. Coal samples were analyzed through non-destructive water immersion experiments, NMR and uniaxial compression acoustic emission tests, and X-ray microscopic imaging. The temporal and spatial changes in the moisture content, crack propagation, and damage characteristics of the coal samples were studied before and after water immersion. The results of this study have important reference value for analyzing the stability of coal pillars and the surrounding rock under the action of water, and especially for the design of coal pillar dam bodies in coal mines with groundwater reservoirs.

\section{EXPERIMENTAL SCHEME}

\section{Collection and Preparation of Coal Samples}

The coal samples were processed into a standard cylindrical test piece of $\varphi 50 \mathrm{~mm} * \mathrm{H} 100 \mathrm{~mm}$ (ISRM, 1978; Jaeger et al., 2007). A total of 30 coal samples were selected which had smooth surfaces on their upper and lower faces, whose parallelism error did not exceed $0.05 \mathrm{~mm}$, and whose diameter error of the upper and lower faces did not exceed $0.3 \mathrm{~mm}$. The samples were divided into six groups, named $\mathrm{W}_{0}, \mathrm{~W}_{1}, \mathrm{~W}_{2}, \mathrm{~W}_{3}, \mathrm{~W}_{4}$, and $\mathrm{W}_{5}$, which showed moisture contents of $0,3.79,6.10,9.17$ (one water immersions), 11.01 (two water immersions), and 11.68\% (three water immersions), respectively. For each water immersion, the sample was dried and then immersed in water to saturation. To reduce the error, the moisture content of each group was measured three times and the average was taken. A total of 18 coal samples were used for the subsequent testing. The physical characteristics of coal samples are shown in Table 1. 
TABLE 1 | Physical characteristics of coal samples.

\begin{tabular}{lc}
\hline Type of coal samples & Long-flame coal \\
\hline Buried depth (m) & 200 \\
Hardness & $\mathrm{f}<3$ \\
Degree of fissure development & Comparative development \\
Initial water moisture (\%) & $\leq 15$ \\
Ash (\%) & $\leq 6.2$ \\
Sulfur content (\%) & $\leq 0.5$ \\
Phosphorus content (\%) & $\leq 0.05$
\end{tabular}

\section{Experimental Equipment}

The samples were immersed in water using a rock water content continuous weighing machine (Figure 1) which was independently constructed by the research team. The device was connected to a humidifier and a sealed box by a plastic hose. After the humidifier is opened, water mist enters the box through the hose, which creates a highhumidity environment inside the box. The coal samples were directly placed in the water, which causes them to crack and disintegrate; however, the device can keep the sample structure intact during immersion. The internal moisture distribution of the coal samples was measured using a MesoMR cabinet magnetic resonance imager (NiuMai, Shanghai, China). This imager has a fast analysis speed, simple and convenient operation, does not influence the health of the operator or the surrounding environment, is non-destructive, and has little influence on the subsequent testing. After the coal sample immersion was completed, a uniaxial compression acoustic emission measurement system (Figure 2) was used to study the variation law and failure characteristics of the pore and fracture structure of the coal samples during the uniaxial compression process. The system was controlled by a CMT5305 microcomputer servo control machine (SanSi, Shanghai, China) and a PCI-2 acoustic emission system (Physical Acoustics, Princeton Junction, NJ, United States). Finally, the spatial distribution of the fractures of the damaged samples was analyzed using a high-resolution three-dimensional nondestructive X-ray microscopic imaging system (Xradia 510 Versa, Carl Zeiss AG, Heidenheim, Germany). The system includes an X-ray source, an inspection station, an objective lens, a CCD camera, and other hardware. Additionally, the system is equipped with the "Scout-and-Scan Control System" data acquisition software, the XM Reconstructor three-dimensional tomography image reconstruction software, the XM Controller software, and other software. This system allows the microscopic imaging of the coal samples, including the spatial distribution of pores and fissures.

\section{Experimental Method}

Before the non-destructive water immersion experiment, the coal samples were dried at $105-110^{\circ} \mathrm{C}$ for $24 \mathrm{~h}$ using a blastdrying oven (model 101-1B; XinYi, Shanghai, China). It should be noted here that the higher drying temperature will have a certain effect on the microstructure of the coal simples, and this effect can be studied in the future to further reduce the effect of this factor on the experiment. After the sample drying was completed and the temperature of the drying box had stabilized to room temperature, the coal sample was removed from the box and weighed. This weight represents the dry mass of the coal sample. Subsequently, the dried samples were sealed and stored. Then, nine coal samples were selected to remove impurities and deposits on the surface of the samples and ensure the structural integrity of the sample. Then, water absorption tests were carried out on the coal samples using the rock water content continuous weighing machine (Figure 1). According to previous research results, the water absorption process of coal samples is roughly divided into three stages (Roshan et al., 2015; Yao et al., 2016): (1) a rapid water absorption phase; followed by (2) a slow water absorption stage; followed by (3) a gradual stabilization stage. So we weighed the water moisture per hour for the first $10 \mathrm{~h}$ of water immersion, and we measured the water moisture every $3 \mathrm{~h}$ after $10 \mathrm{~h}$. When the mass difference of the sample before and after weighing was less than $0.01 \mathrm{~g}$, it was assumed that the coal sample had reached water saturation. The uniaxial compression and acoustic emission tests were carried out simultaneously. The test loading mode was displacement loading, and the loading rate was $0.5 \mathrm{~mm} / \mathrm{min}$. Loading was applied to the coal sample until the sample failed. A total of eight acoustic emission probes were used; each probe was placed at a distance of $10 \mathrm{~mm}$ from the upper and lower faces of the sample. The probe arrangement is shown in Figure 7. The detection threshold parameters were set to PDT $=50 \mu \mathrm{s}, \mathrm{HDT}=200 \mu \mathrm{s}$, and HLT $=300 \mu \mathrm{s}$. The detection threshold was $40 \mathrm{~dB}$ and the magnification was $40 \mathrm{~dB}$.

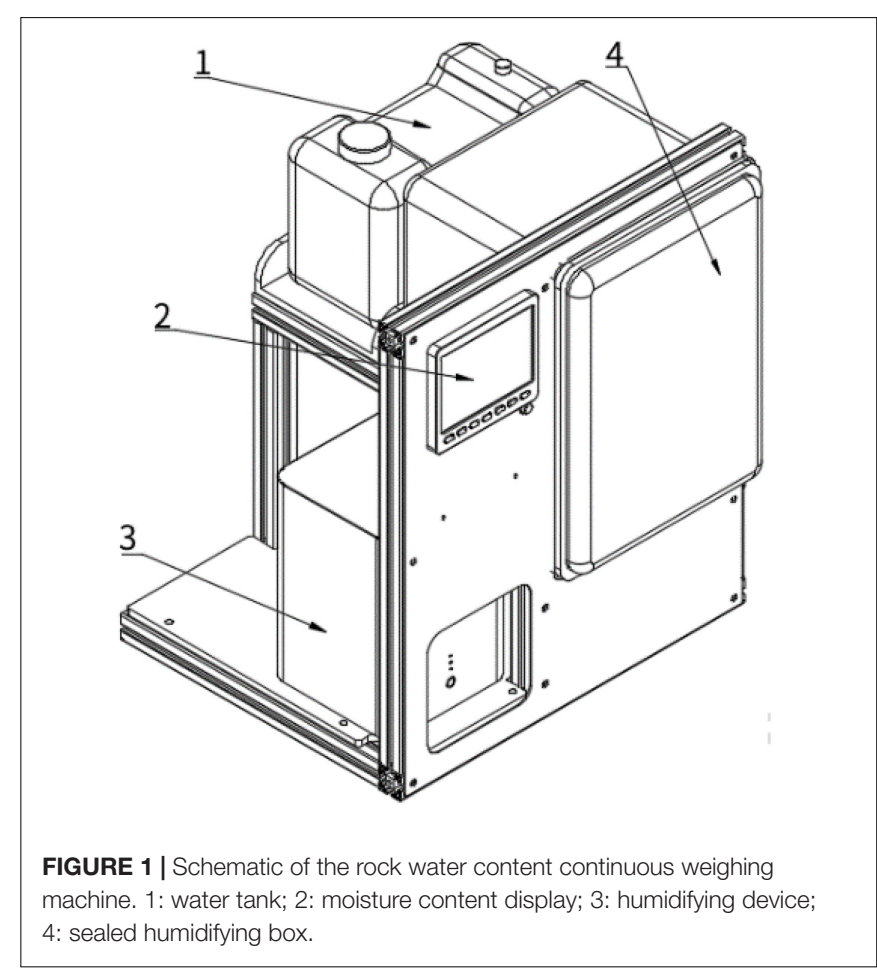




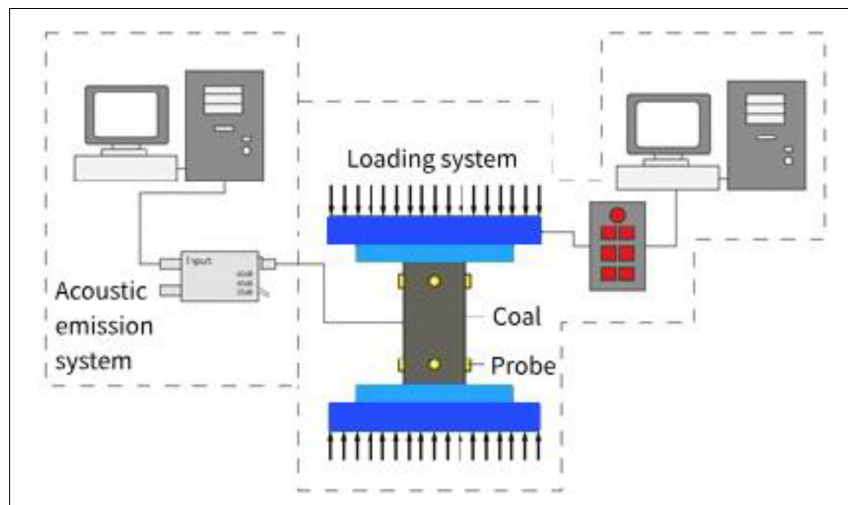

FIGURE 2 | Schematic of the experimental uniaxial compression system.

\section{CHANGES IN COAL SAMPLE WATER CONTENT AND MICROSCOPIC STRUCTURAL CHARACTERISTICS}

\section{Changes in Coal Sample Water Content With Immersion Time and Immersion Frequency}

The observed relationship between the duration and frequency of water immersion and the moisture content of the coal samples is shown in Figure 3.

From Figure 3, it can be seen that there is an exponential relationship between the moisture content of the coal samples and both the length and frequency of water immersion; with increasing immersion time and immersion frequency, the water content first increases rapidly, and then this increase decelerates. The correlation coefficients of the two fitted curves are both close to 1 , indicating that the experimental data is well fitted.

As shown in Figure $\mathbf{3 A}$, the water absorption process is divided into three stages: (1) a rapid water absorption stage $(0 \sim 10 \mathrm{~h})$; (2) a slow water absorption stage (10 30 h); and (3) a stable water absorption stage $(\geq 30 \mathrm{~h})$. The saturated moisture content of the test coal sample is $9.17 \%$. In Stage 1, the water content of the coal sample increases rapidly; in Stage 2, the water absorption rate of the coal sample gradually decreases; and in Stage 3 , the water content of the coal sample does not change substantially. In the initial stage of water immersion, hydrophilic substances and primary pores and fissures absorbed water. In the later stage, as the coal samples continued to absorb water, the weakening of water creates more pores and fractures and absorbs water again until saturation. Based on the observed changes of the water content of the coal samples with increasing immersion time, three coal samples with water immersion times of 5,10 , and $30 \mathrm{~h}$ were selected for further testing; the water contents of these samples were $3.79,6.10$, and $9.17 \%$, respectively.

As shown in Figure 3B, the moisture content of the coal samples increased as the immersion frequency increased. Between the first and second immersions, the moisture content of the coal samples increased from 9.17 to $11.01 \%$, an increase of $20.07 \%$. Between the second and third immersions, the
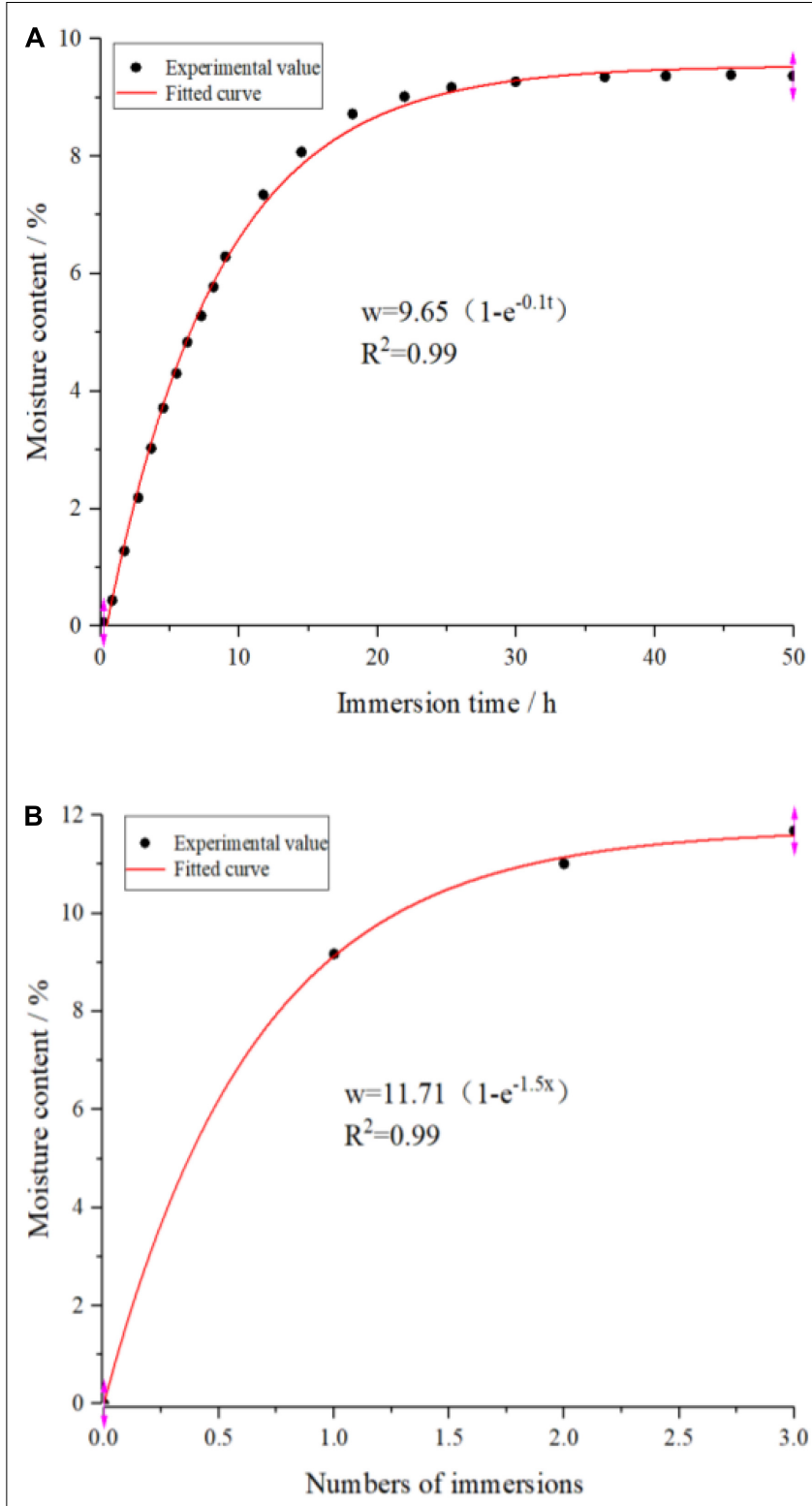

FIGURE 3 | Moisture content of coal samples vs. (A) duration of water immersion and (B) frequency of water immersion. $\mathbf{W}$ indicates the moisture content of the coal sample (in \%); $\mathrm{t}$ is the water immersion time (in h); $\mathrm{x}$ is the number of immersions; and $R^{2}$ is the correlation coefficient of the fitted curve.

moisture content of the coal increased from 11.01 to $11.68 \%$, a $6.09 \%$ increase. Based on the observed relationship between the frequency of water immersion and the sample moisture content, the moisture content of the coal samples will stabilize after repeated water immersion. This is due to the fact that, after the coal sample is saturated with water and then dried, the internal pores and cracks continue to develop, and the moisture content will therefore increase further when the sample is re-immersed. After the internal structure of the sample is fully developed, the moisture content will stabilize. We selected a representative coal sample from each of the six groups for subsequent testing. 


\section{Spatial Distribution of Moisture in Coal Samples}

Since coal is a weakly magnetic substance, and the $\mathrm{C}_{13}$ nuclear and $\mathrm{H}_{1}$ nuclear signals in the coal sample will be shielded during the NMR analysis, its magnetism will not affect the results of this analysis. The spatial distributions of the coal sample moisture contents, as determined using NMR, are shown in Figure 4.

Note: $\mathrm{C}_{13}$ refers to carbon $(\mathrm{C})$, which has a relative atomic mass of 13 , and $\mathrm{H}_{1}$ refers to hydrogen $(\mathrm{H})$, which has a relative atomic mass of 1 .

As shown in Figure 4A, the water content of the coal samples varies along the length axis. This variation is caused by fissures and other heterogeneities in the coal samples, which shows that fractures are well developed and the water content of the waterrich mineral enrichment layer is high. The way that the coal sample is placed during the non-destructive water immersion test has a certain influence on the spatial distribution of the internal moisture of the coal sample; this is manifested by the fact that the water content is greater in the bottom part of the coal sample due to the action of gravity. For the coal sample with a water content of $3.79 \%$, the water content in the middle of the sample was almost zero and there was less variation in water content in this area; this indicates that the structure of the middle layer of the coal sample is more complicated and contains more nonhydrophilic substances. For the coal samples with water contents of 6.10 and $9.17 \%$, with increasing moisture content, the degree of internal water diffusion increases and the spatial distribution of water content becomes more uniform. It should be noted that the dry coal sample had a very small amount of internal water. This is due to the presence of bound water inside the coal sample and the inhalation of a small amount of air by the coal sample during the testing.

As shown in Figure 4B, the spatial distribution of the moisture contents of the samples varied for different immersion frequencies. With increasing water immersion frequency, the water intensifies the internal damage of the coal sample, the pores and cracks of different layers are developed, and the water content of the sample increases. Compared with the sample which was immersed in water only once, With increasing immersion frequency, the water content of the coal samples increased steadily and the spatial distribution of water became more uniform.

\section{Pore and Fracture Characteristics of Water-Bearing Coal Samples}

Yao and Liu (2012) found that coal can be regarded as a multi-structure system composed of coal matrix blocks and macro-fractures, micro-fractures, macro-pores, microfractures, and so on. The results of the NMR analysis, which show typical triple-peak $\mathrm{T}_{2}$ spectra, are shown in Figure 5. In these spectra, the peaks representing the micro-pores are mainly distributed at $0.1 \sim 10 \mathrm{~ms}$, the peaks representing the large meso-pores are mainly distributed at $20 \sim 50 \mathrm{~ms}$, the peaks representing the fissures are mainly distributed at $>100 \mathrm{~ms}$. Therefore, the microstructure of the coal sample can be inferred based on the location of the peak value of the $T_{2}$ spectrum curve (Yao et al., 2010; Cai et al., 2013).

As shown in Figure 5, the $T_{2}$ spectra were zoned according to their triple-peak structure; these zones were termed zone I, zone II, and zone III. Based on the $\mathrm{T}_{2}$ spectra of the coal samples, it can be inferred that the micro-structure characteristics of the coal samples have commonalities: the development of micro-pores are dominant, followed by the development of medium-large pores, fissures are developed, and the connectivity between the pores is good. A low-intensity NMR signal was measured for the dry coal sample, with the signal amplitude being about $1 / 10$ of that of the moist samples. The results of the NMR analysis show that the internal structure of the sample is dominated by micro-pores. With increasing water content and increasing water immersion frequency, the $\mathrm{T}_{2}$ relaxation times of micro-pores and medium-large pores gradually increased; this suggests that the micro-pores and medium-large pores gradually developed into larger pores, which in turn indicates that the presence of water caused internal damage to the coal. The gradual increase in signal amplitude that is observed above $100 \mathrm{~ms}$ with increasing water content indicates that the micropores and the medium-large pores gradually develop and form cracks with increasing water content. The peak area of the $\mathrm{T}_{2}$ spectrum represents the degree of development of internal cracks in the coal sample. From Figures 5D-F, it can be seen that double water immersion increased the moisture content of the sample by $26.07 \%$ compared with single immersion, and triple water immersion increased the moisture content by an additional $2.40 \%$.

\section{ANALYSIS OF THE FISSURE EXPANSION AND FAILURE FORM OF WATER-BEARING COAL}

Many previous experimental researches have been conducted on the influence of moisture content and water immersion frequency on coal strength (e.g., Hashiba and Fukui, 2015; Yao et al., 2016). The conclusions of these studies can be summarized as follows: the uniaxial compressive strength of dry coal samples is large. The most severe damage to the coal samples was a large collapse phenomenon. With increasing moisture content, the mechanical properties of the coal samples showed a downward trend, and the severity of the damage gradually decreased. The uniaxial compressive strength, elastic modulus, and strain softening coefficient of coal samples are negatively correlated with moisture content, that is, with increasing sample immersion time and immersion frequency, the plasticity of coal samples increases and brittleness reduces. With increasing immersion time, the decline of the elastic modulus of the coal samples gradually reduced. The compressive strength and elastic modulus of the coal samples decreased greatly after initial saturation, and continued to decrease, albeit at a lower rate, with increasing immersion frequency. The conclusions that can be drawn from this analysis are consistent with previous studies (Yao et al., 2016), so they will not be repeated here. 

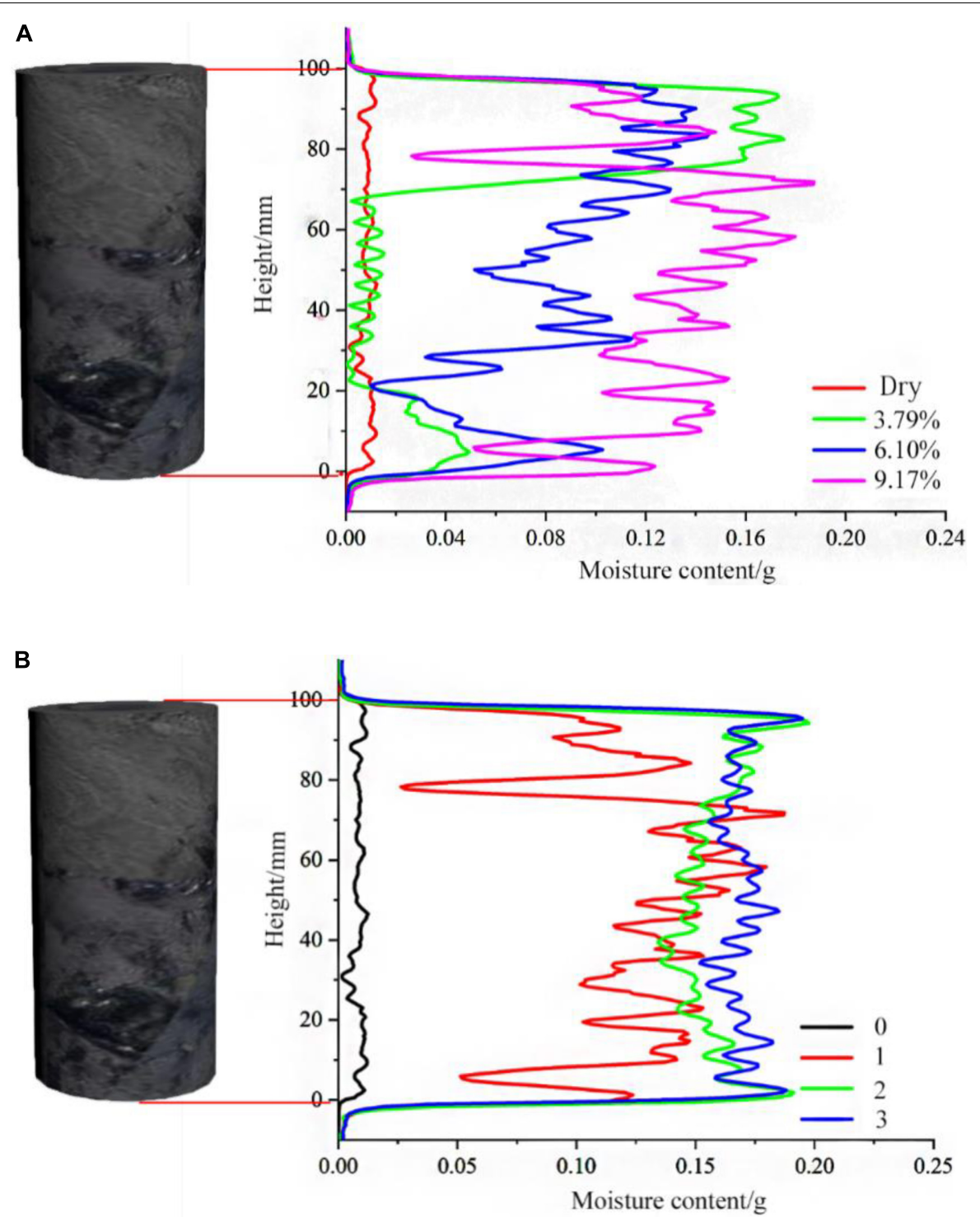

FIGURE 4 | Spatial distributions of coal specimen moisture contents (A) for samples with various moisture contents (\%) and (B) for samples which were subjected to various immersion frequencies.

\section{Study of Acoustic Emissions During the Uniaxial Compression of Water-Bearing Coal Samples}

Acoustic emission localization technology is commonly used to study the evolution law of coal-like fissures (Lei et al., 2016). Measurements of acoustic emissions can be used to infer the development of internal cracks in a sample. The fissure evolution law is intuitive, and the damage process inside the coal body can be observed in real time using acoustic emission localization. In order to study the evolution law of fissures in water-bearing coal samples under uniaxial compression, the obtained acoustic emission localization data was processed. Figure 6 shows a realtime map of acoustic emission events during the compression of coal samples with different water contents.
As shown in Figure 6, as the moisture content of the coal samples increases, the time required to reach the peak stress reduces, from $832 \mathrm{~s}$ in the dry coal sample to $184 \mathrm{~s}$ in the sample which was immersed three times. As more water enters the sample, this causes the internal fissures of the coal to continue to develop, which in turn causes the internal structure of the coal sample to become more fragile and more susceptible to damage under pressure.

In the early stage of uniaxial compression, acoustic emissions are fewer and are mainly distributed in the interior of the coal sample. As the load increases, acoustic emissions occur at a greater rate, and show a trend of expansion from the interior of the coal sample toward its surface. Near the peak stress, the number of acoustic emissions gradually increases, and the final acoustic emissions cluster along the macroscopic fracture 

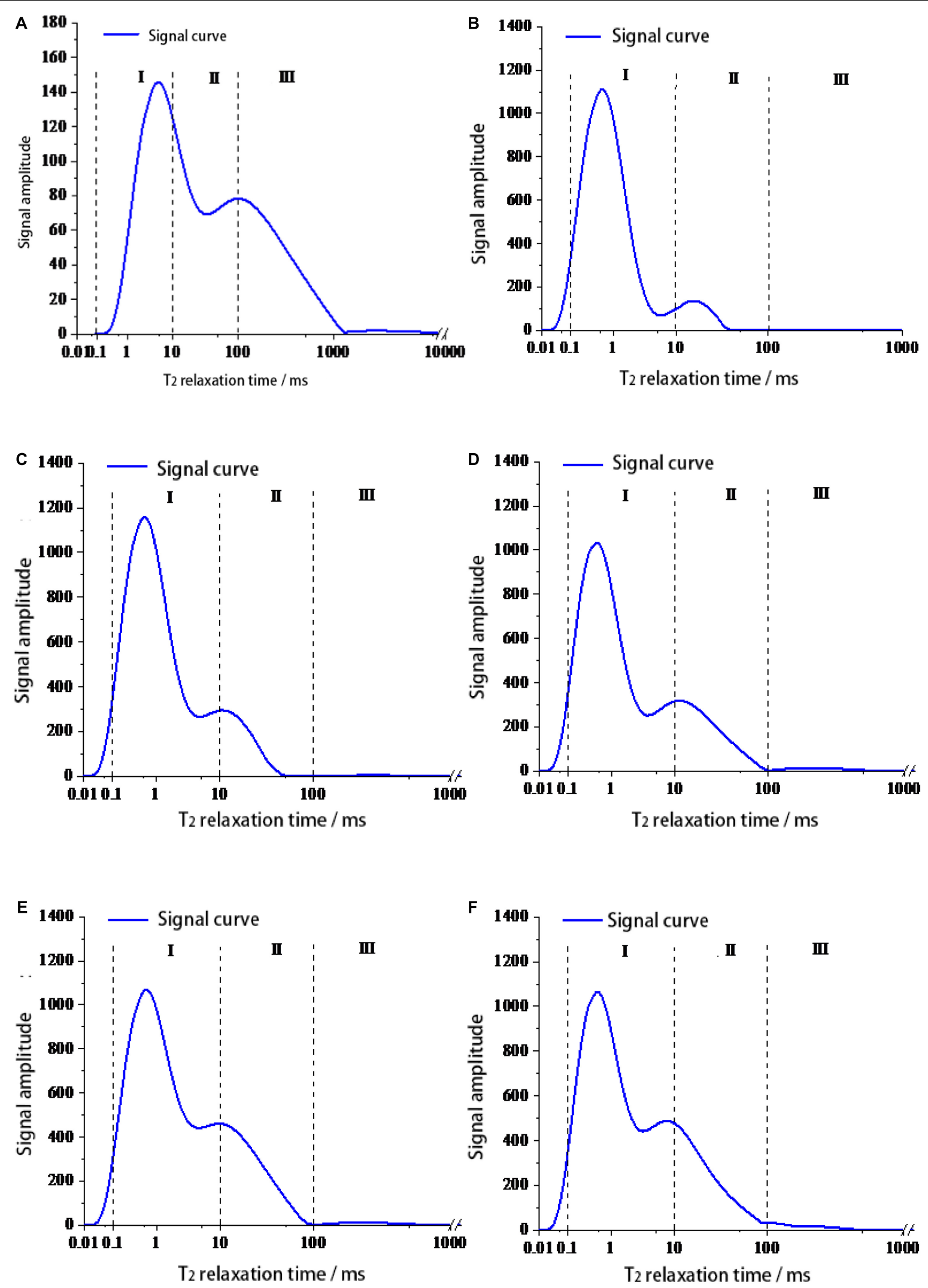

FIGURE 5 | T 2 relaxation time curves of coal samples with different moisture contents. (A) Dry sample. (B) Moisture content of 3.79\%. (C) Moisture content of 6.10\%. (D) Moisture content of 9.17\%. (E) Moisture content of 11.01\% (two immersions). (F) Moisture content of 11.68\% (three immersions). 


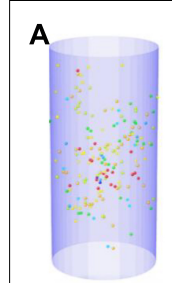

(a) $364 \mathrm{~s}$

B

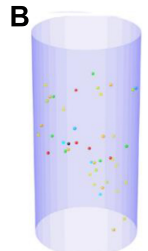

(a) $324 \mathrm{~s}$

C

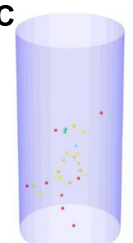

(a) $300 \mathrm{~s}$

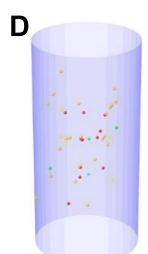

(a) $300 \mathrm{~s}$

$E$

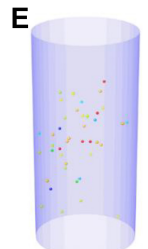

(a) $159 \mathrm{~s}$

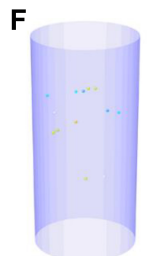

(a) $69 \mathrm{~s}$

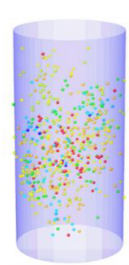

(b) $498 \mathrm{~s}$

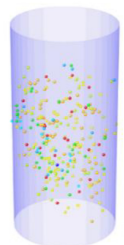

(b) $528 \mathrm{~s}$

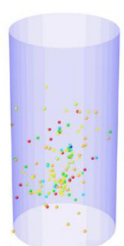

(b) $450 \mathrm{~s}$

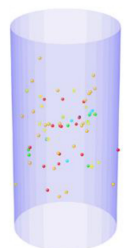

(b) $459 \mathrm{~s}$

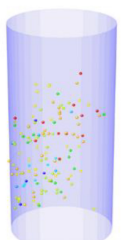

(b) $249 \mathrm{~s}$

(b) $92 \mathrm{~s}$

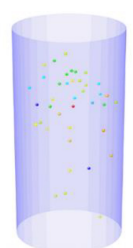

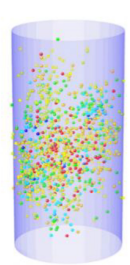

(c) $612 \mathrm{~s}$

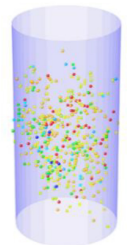

(c) $603 \mathrm{~s}$

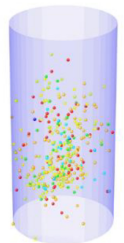

(c) $600 \mathrm{~s}$

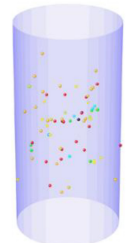

(c) $528 \mathrm{~s}$

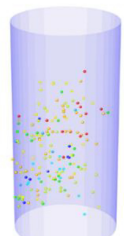

(c) $312 \mathrm{~s}$

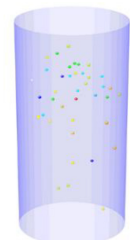

(c) $155 \mathrm{~s}$

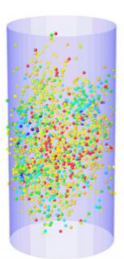

(d) $722 \mathrm{~s}$

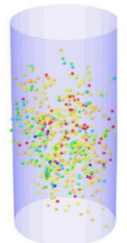

(d) $639 \mathrm{~s}$

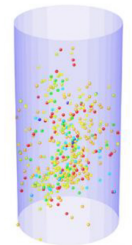

(d) $627 \mathrm{~s}$

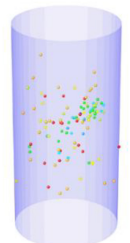

(d) $607 \mathrm{~s}$

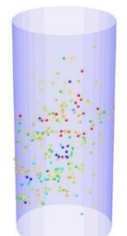

(d) $374 \mathrm{~s}$

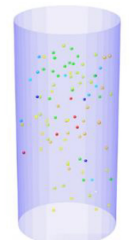

(d) $179 \mathrm{~s}$

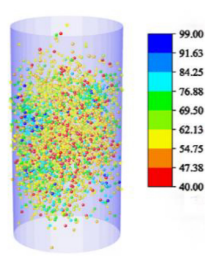

(e) $832 \mathrm{~s}$

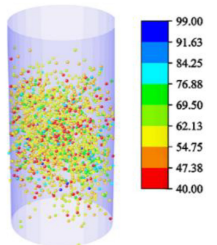

(e) $722 \mathrm{~s}$

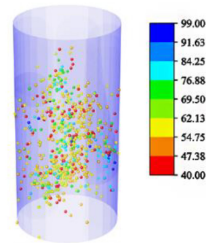

(e) $670 \mathrm{~s}$

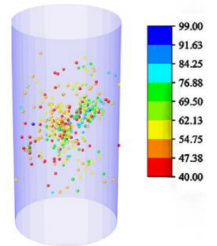

(e) $750 \mathrm{~s}$

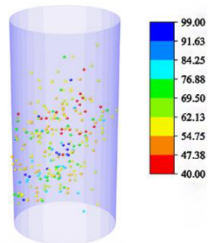

(e) $398 \mathrm{~s}$

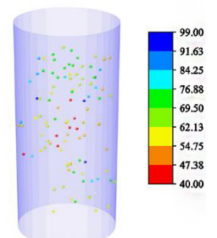

(e) $184 \mathrm{~s}$
FIGURE 6 | Acoustic emissions measured during the uniaxial compression of coal samples. (A) Dry sample. (B) Moisture content of 3.79\%. (C) Moisture content of $6.10 \%$. (D) Moisture content of $9.17 \%$. (E) Twice-immersed sample. (F) Thrice-immersed sample. Each point represents an acoustic emission event, and the colors represent the amplitude of the acoustic emission event. surface. Acoustic emissions are most densely distributed when the dry coal sample reaches the peak stress. With increasing water content, the number of acoustic emissions gradually reduced, with the fewest emissions being observed in the sample which had been immersed three times. The intensity of acoustic emissions can be used to characterize the degree of coal sample damage and the development of fractures. The most severe damage was observed in dry coal samples. With increasing moisture content, the severity of coal sample damage gradually reduced. The results of the analysis suggest that due to the weakening effect of water on the coal samples, the damage to internal microstructure is developed, the energy required for the destruction of the samples is reduced, and the degree of damage is not severe; therefore, the number of detected acoustic emission events was small for samples with high moisture contents. Therefore, it can be summarized that: in the case of low moisture contents (including the dryness), the acoustic emission events are concentratedly distributed, the energy accumulation is higher, so the rupture is more severe, and in the case of high moisture contents, there are fewer acoustic emission events and the internal structure is developed. The energy accumulation is lower and is mainly released from the shear fracture surface, the destruction of the coal samples structure is relatively complete.

\section{Analysis of the Macroscopic Failure Characteristics of Water-Bearing Coal Samples}

Subsequently, the damage characteristics of the water-bearing coal samples were determined using the results of the compression tests together with the spatial distribution of water content shown in Figure 4, the high-amplitude signal of the sound emission events in Figure 6, and the macroscopic performance of the coal samples. The macroscopic failure modes of the samples and the corresponding crack propagation maps are shown in Figure 7.

As shown in Figure 7, the dry coal sample mainly underwent tensile failure, with the development of several fracture faces along the axial direction. This is due to the fact that the transverse tensile stress exceeded the ultimate tensile strength of the coal sample, which is the result of the Poisson effect. The damage occurred suddenly and mostly involved cracking. The emission of high-amplitude acoustic emissions is consistent with the position of cracked and collapsed coal. The coal sample with a moisture content of $3.79 \%$ experienced less damage and weakening than the dry coal sample; the rupture shows a relatively large area of block caving, similar to that observed in the failure of the dry coal sample. In the sample with a moisture content of $3.79 \%$, the accumulation of high-amplitude acoustic emissions was denser on one side of the sample, and the macroscopic damage on this side was also more serious. The ruptures observed in the dry sample and in the sample with $3.79 \%$ water are similar. In these two low-moisture coal samples, the primary microstructure inside the sample plays a major role in the rupture process.

With increasing moisture content, the internal pores and fissures of the coal samples continue to develop. In samples 


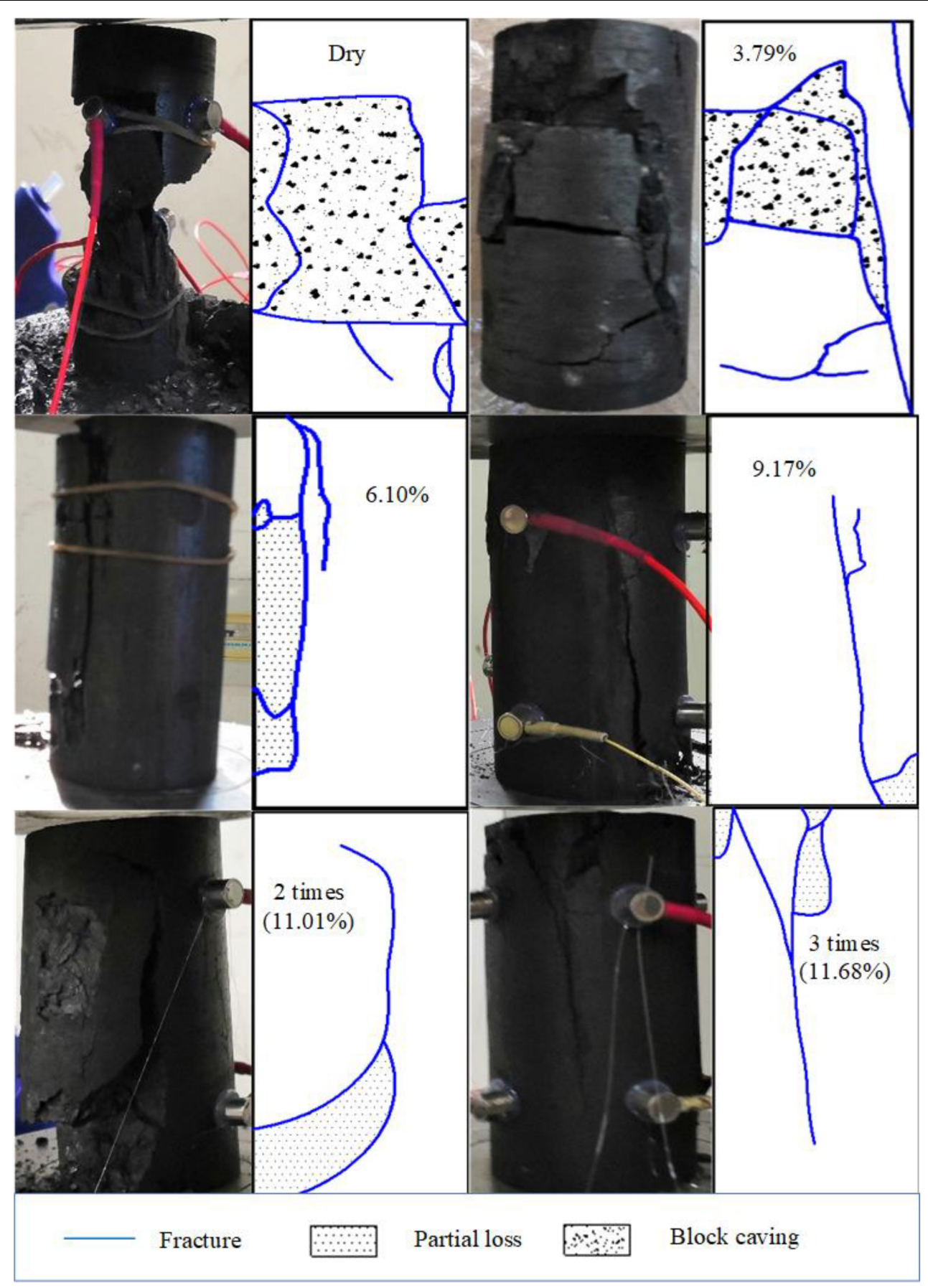

FIGURE 7 | Failure characteristics of coal samples under uniaxial compression.

with moisture contents above $3.79 \%$, the macroscopic rupture positions and the spatial distribution of water tend to be similar; macroscopic rupture occurs at a location where there is a relatively large amount of internal moisture. The coal samples with moisture contents of 6.10 and $9.17 \%$ have a different spatial distribution of moisture compared to the two drier samples, with the moisture mainly being distributed in the lower part of the samples. Furthermore, in the samples with moisture contents of 6.10 and $9.17 \%$, the rupture damage was milder, and fewer acoustic emissions were observed, compared to the two drier coal samples, and the drop-off position is consistent with the spatial distribution of water. Compared with the coal samples which were immersed only once, the sample which was immersed twice had a higher moisture content, and the internal damage was also more serious. Therefore, it can be seen that the water content has a significant influence on the 


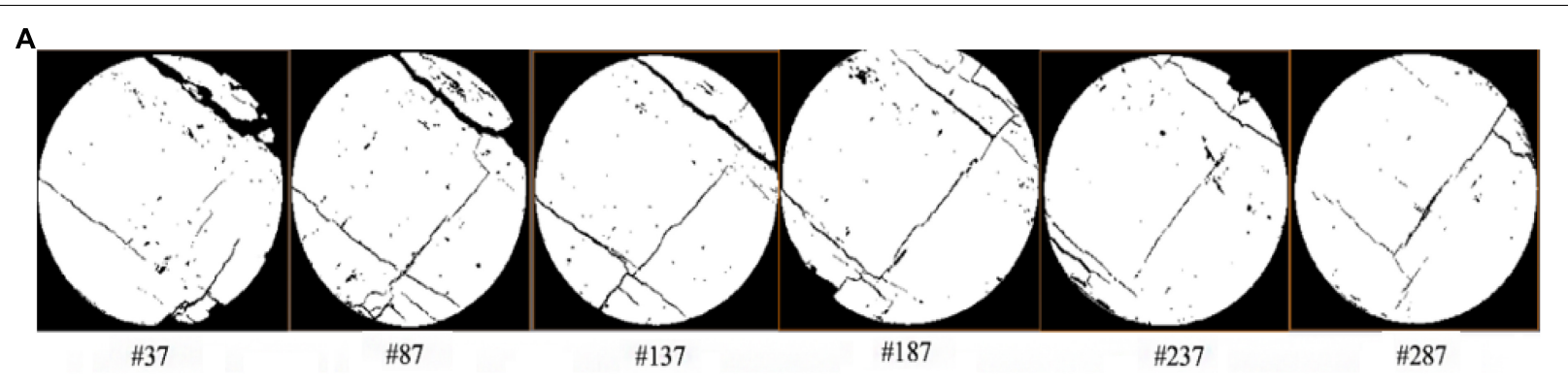

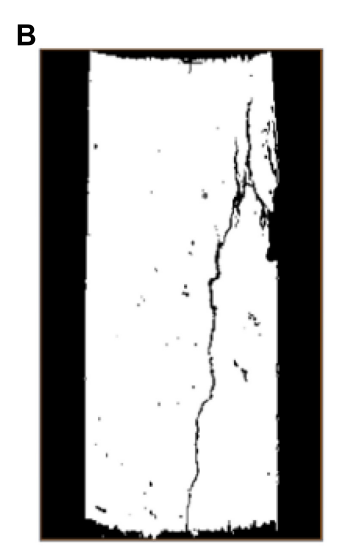

$\# 37$

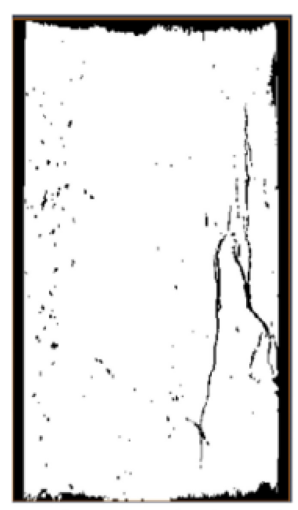

\#87

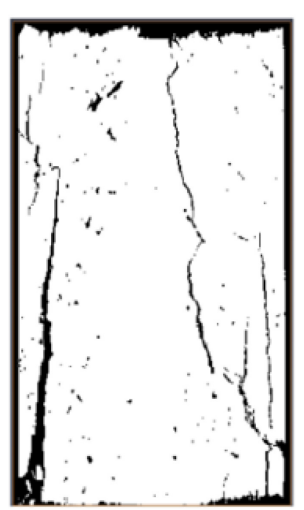

$\# 137$

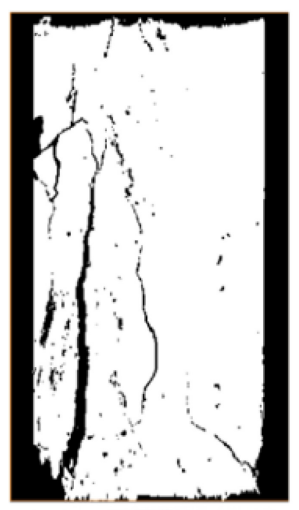

\#187

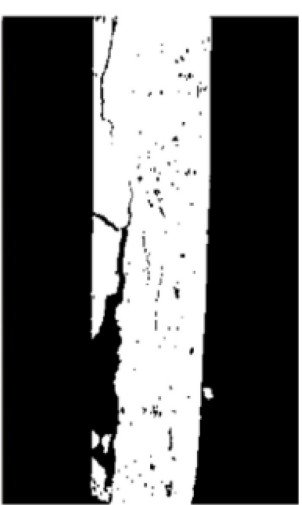

\#237

FIGURE 8 | Images showing the fracturing (after failure induced by uniaxial compression) at various positions in the coal sample with $6.10 \%$ water. (A) Axial slices. (B) Radial slices. White areas represent the coal matrix, while black areas represent pores and cracks.

structure of the coal samples, and in the samples which were immersed more than once, the development of the fracture surface extends from the middle to the upper and lower parts of the samples. The coal sample which was immersed in water three times reached saturation. Compared to the samples which were immersed only once, in the samples which were immersed more than once, fracture development is basically stable, the spatial distribution of water is relatively uniform, and the effect of water on cracking is more serious than in the samples which were immersed only once. The degree of damage was lowest in the sample which was immersed three times, with the macroscopic damage being visible as a shear crack throughout the sample. Moreover, the amplitude of acoustic emissions was lowest for this sample.

With increasing moisture content, the degree of damage to the coal samples gradually reduces, and the degree of failure also gradually reduces. The failure of the coal samples showed the characteristics of large-scale collapse, partial detachment, and penetration cracks. When the moisture content is low, the failure mode of the coal samples is mainly tensile. However, with increasing numbers of water immersions, the coal sample failure form changes from tensile failure to tensile-shear composite failure. This suggests that with increasing moisture content, the internal particle cementation is weakened, the surface shear strength is reduced, and the friction coefficient of the fracture surface is reduced, which increases the possibility of shear failure. The essential reason for this is that, with increasing moisture content, water has a complex physicochemical effect on coal. Water molecules weaken the interaction between coal molecules and reduce the coupling force between coal molecules (Zou and Li, 2015). The friction between particles increases the plasticity of the coal sample, resulting in a weakening of its mechanical properties. At the same time, $\mathrm{OH}^{-}$has a strong coupling effect on coal samples, which leads to changes in their microstructure and weakens their mechanical properties (Hashiba and Fukui, 2015; Xu et al., 2015; Yu et al., 2015). Additionally, when the internal pores and cracks of the coal sample are filled with water and subjected to load, a high pore pressure will be generated inside, which will reduce the compressive stress between the particles, thereby reducing the shear strength of the coal sample and making shear damage more likely to occur on a macroscopic scale.

\section{Analysis of the Microscopic Failure Characteristics of Water-Bearing Coal Samples}

In order to further explore the meso-scale failure characteristics of water-bearing coal samples (based on the analysis of coal samples after rupture), a chromatographic test was carried out on two representative samples after the completion of the compression test: (1) the sample with a water content of $6.10 \%$; and (2) the sample which was immersed three 


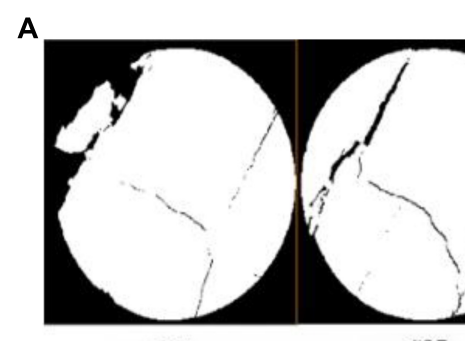

\#37
\#87

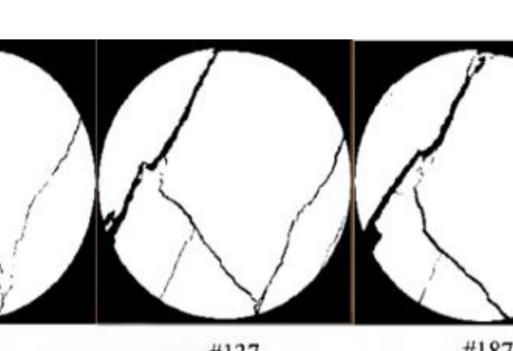

\#137

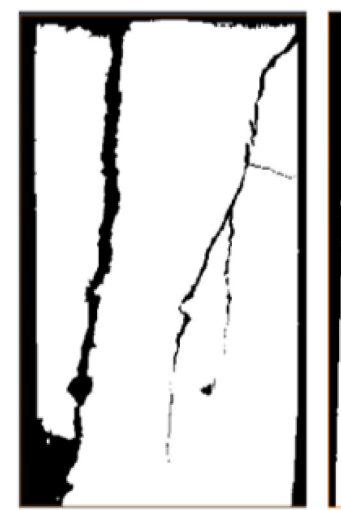

\#87

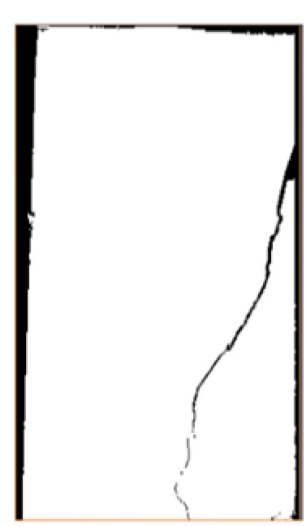

$\# 137$

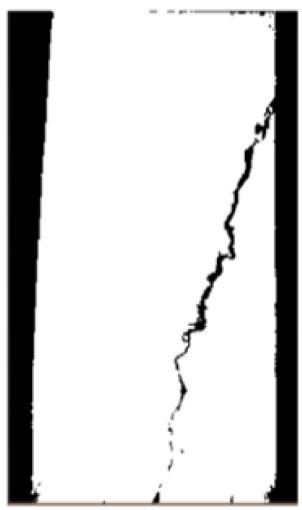

\#187

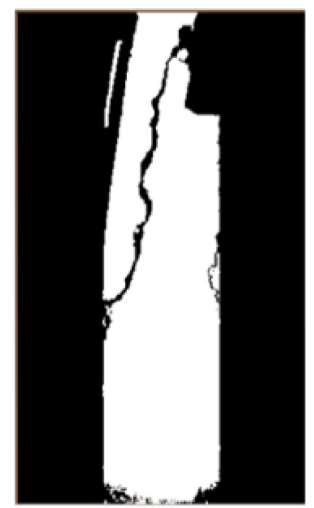

\#237

FIGURE $\mathbf{9}$ | The same as Figure $\mathbf{8}$ but for the coal sample which was immersed in water three times.

times. The Avizo 3D visualization software version 6.2 (Thermo Fisher Scientific, Waltham, MA, United States) was used to divide the coal sample into 300 layers, and every 50 layers one layer was selected for analysis, as shown in Figures 8, 9.

The results of the microscopic scanning in Figure $\mathbf{8}$ show that the coal sample with a moisture content of $6.10 \%$ mostly exhibits X-shaped conjugate-slope shear failure or single-slope shear failure. This sample has many internal cracks and large pores, and the fragmentation is more serious, being accompanied by local shedding. The failure characteristics of this sample are more complicated than those of the sample which was immersed three times, and its failure mode is tensile-shear. As shown in Figure 9, in the coal sample which was immersed in water three times, fracturing was less serious and the integrity of the fractured block is higher. This difference can be attributed to the repeated immersions. The internal damage to this sample is severe, suggesting that its compressive strength had been greatly reduced. With increasing water content, the internal particle cementation of the coal sample is weakened, and the surface shear strength and coefficient of the fracture surface are reduced, and the possibility of shear failure is therefore increased. The results of the presented microscopic structural analysis are consistent with the results of the macroscopic analysis (see Section Analysis of the Macroscopic Failure Characteristics of Water-Bearing Coal Samples). It also shows that with the increase of the moisture content, the failure of coal samples shows a trend from tensile failure to tensile-shear composite failure.

\section{CONCLUSION}

In this work, we systematically studied the temporal and spatial evolution of the internal moisture of samples of 5-2 coal from the Daliuta coal mine, China, using coal samples with different moisture contents and different water immersion frequencies. Additionally, we studied the development of pores and fissures in these samples, as well as their failure characteristics, using a uniaxial compression test and NMR analysis. The following main research results were obtained:

(1) With increasing water immersion time and increasing number of immersions, the moisture content of the coal samples increased exponentially, and the water distribution gradually became more spatially uniform;

(2) The internal structure of the dry coal sample before loading is dominated by micro-pores and relatively few cracks. For the samples which were immersed in water two times, the peak area of the $\mathrm{T}_{2}$ spectrum was $26.07 \%$ larger than for the samples which were immersed only once; additionally, for the samples which were immersed in water three times, the peak area of the $\mathrm{T}_{2}$ spectrum was $2.40 \%$ higher than for the samples which were immersed in water twice. For the coal samples with low moisture contents $(0,3.79$, and $6.10 \%)$, 
after loading, the internal pores and fissures developed significantly, and the degree of cracking was severe. However, for the coal samples with high moisture contents (9.17, 11.01, and $11.68 \%$ ), the microstructure was less developed and the loading damage was milder;

(3) As the moisture content of the coal samples increases, the time required for the sample to reach peak stress reduces, the number of acoustic emissions decreases, and the degree of acoustic-emission aggregation decreases. Additionally, with increasing moisture content, the spatial distribution of water becomes more uniform, and the concentration of high-amplitude acoustic emissions is consistent with the fracture form;

(4) With increasing moisture content, the degree of damage to coal samples following uniaxial loading gradually reduces. At microscopic level, the rupture form in coal with a low moisture content is dominated by large caving, localized shedding, and cracking; however, the rupture form in coal with a high moisture content leads to crack penetration. Microscopically speaking, the internal pores and fractures in coal samples with a low moisture content are more developed, and these samples have significant internal fragmentation. However, in coal samples with a high

\section{REFERENCES}

Cai, Y. D., Liu, D. M., Pan, Z. J., Yao, Y. B., Li, J. Q., and Qiu, Y. K. (2013). Petrophysical characterization of Chinese coal cores with heat treatment by nuclear magnetic resonance. Fuel 108, 292-302. doi: 10.1016/j.fuel.2013.0 2.031

Chen, L. H., Chen, W. C., Chen, Y. C., Benyamin, L., and Li, A. J. (2015). Investigation of hydraulic fracture propagation using a post-peak control system coupled with acoustic emission. Rock Mech. Rock Eng. 48, 1233-1248. doi: 10.1007/s00603-014-0620-y

Chen, T., Yao, Q. L., Wei, F., Chong, Z. H., Zhou, J., Wang, C. B., et al. (2017). Effects of water intrusion and loading rate on mechanical properties of and crack propagation in coal-rock combinations. J. Central S. Univ. 24, 423-431. doi: $10.1007 /$ s11771-017-3444-6

Daraei, A., and Zare, S. (2018). Effect of water content variations on critical and failure strains of rock. KSCE J. Civil Eng. 22, 3331-3339. doi: 10.1007/s12205018-0592-7

Gu, D. Z. (2015). Theory framework and technological system of coal mine underground reservoir. J. China Coal Soc. 40, 239-246.

Gu, D. Z., Yan, Y. G., Zhang, Y., Wang, E. Z., and Cao, Z. G. (2016). Experimental study and numerical simulation for dynamic response of coal pillars in coal mine underground reservoir. J. China Coal Soc. 41, 1589-1597.

Hashiba, K., and Fukui, K. (2015). Effect of water on the deformation and failure of rock in uniaxial tension. Rock Mech. Rock Eng. 48, 1751-1761. doi: 10.1007/ s00603-014-0674-x

Heggheim, T., Madland, M. V., Risnes, R., and Austad, T. (2004). A chemical induced enhanced weakening of chalk by seawater. J. Petrol. Sci. Eng. 46, 171-184. doi: 10.1016/j.petrol.2004.12.001

Hu, S. Y., Xiao, C. L., Liang, X. J., Cao, Y. Q., Wang, X. R., and Li, M. Q. (2019). The influence of oil shale in situ mining on groundwater environment: a water-rock interaction study. Environ. Sci. 228, 384-389. doi: 10.1016/j.chemosphere.2019. 04.142

ISRM (1978). International society for rock mechanics commission on standardization of laboratory and field tests: suggested methods for the quantitative description of discontinuities in rock masses. Int. J. Rock Mech. Min. Sci. Geomech. Abstr. 15, 319-368. doi: 10.1016/0148-9062(78)91472-9

Jaeger, J. C., Cook, N. G. W., and Zimmerman, R. (2007). Fundamentals of Rock Mechanics. London: Blackwell. moisture content, the microstructure is less developed and the integrity of the damaged block is higher.

\section{DATA AVAILABILITY STATEMENT}

All datasets generated for this study are included in the article/supplementary material.

\section{AUTHOR CONTRIBUTIONS}

QY was in charge of the main writing part of this manuscript. $\mathrm{CZ}$ was in charge of the experiments and finishing of this manuscript. CT and ZC revised the manuscript. QX assisted in the development of the manuscript experiments. XL reviewed this manuscript finally.

\section{FUNDING}

This work was supported by "the Fundamental Research Funds for the Central Universities” (2018XKQYMS10).

Khazaei, C., Hazzard, J., and Chalaturnyk, R. (2015). Damage quantification of intact rocks using acoustic emission energies recorded during uniaxial compression test and discrete element modeling. Comput. Geotechn. 67, 94102. doi: 10.1016/j.compgeo.2015.02.012

Lei, X. L., Funatsu, T., Ma, S. L., and Liu, L. Q. (2016). A laboratory acoustic emission experiment and numerical simulationof rock fracture driven by a high-pressure fluid source. J. Rock Mech. Geotechn. Eng. 8, 27-34. doi: 10.1016/ j.jrmge.2015.02.010

Mathews, J. P., Campbell, Q. P., Xu, H., and Halleck, P. (2017). A review of the application of X-ray computed tomography to the study of coal. Fuel 209, 10-24. doi: 10.1016/j.fuel.2017.07.079

Moradian, Z., Einstein, H., and Ballivy, G. (2016). Detection of cracking levels in brittle rocks by parametric analysis of the acoustic emission signals. Rock Mech. Rock Eng. 49, 785-800. doi: 10.1007/s00603-015-0775-1

Osselin, F., Saad, S., Nightingale, M., Hearn, G., Desaulty, A. M., Gaucher, E. C., et al. (2019). Geochemical and sulfate isotopic evolution of flowback and produced waters reveals water-rock interactions following hydraulic fracturing of a tight hydrocarbon reservoir. Sci. Total Environ. 687, 1389-1400. doi: 10. 1016/j.scitotenv.2019.07.066

Pan, Z. J., Connell, L. D., Camilleri, M., and Connelly, L. (2010). Effects of matrix moisture on gas diffusion and flow in coal. Fuel 89, 3207-3217. doi: 10.1016/j. fuel.2010.05.038

Roshan, H., Ehsani, S., Marjo, C. E., Andersen, M. S., and Acworth, R. I. (2015). Mechanisms of water adsorption into partially saturated fractured shales: an experimental study. Fuel 159, 628-637. doi: 10.1016/j.fuel.2015.07.015

Verstrynge, E., Adriaens, R., Elsen, J., Van Balen, K., and Leuven, K. U. (2014). Multi-scale analysis on the influence of moisture on the mechanical behavior of ferruginous sandstone. Construct. Build. Mater. 54, 78-90. doi: 10.1016/j. conbuildmat.2013.12.024

Xu, H. N., Liu, J. F., Wang, L., Yang, B. Q., and Yang, H. T. (2015). The weakening effect of hydrostatic pressure on rock mass of different lithology. Environ. Earth Sci. 74, 2489-2497. doi: 10.1007/s12665-015-4255-4

Yao, Q. L., Chen, T., Ju, M. H., Liang, S., Liu, Y. P., and Li, X. H. (2016). Effects of water intrusion on mechanical properties of and crack propagation in coal. Rock Mech. Rock Eng. 49, 1-11.

Yao, Q. L., Li, X. H., Zhou, J., Ju, M. H., Chong, Z. H., and Zhao, B. (2015). Experimental study of strength characteristics of coal specimens after water intrusion. Arab. J. Geosci. 8, 6779-6789. doi: 10.1007/s12517-014-1764-5 
Yao, Y. B., and Liu, D. M. (2012). Comparison of low-field NMR and mercury intrusion porosimetry in characterizing pore size distributions of coals. Fuel 95, 152-158. doi: 10.1016/j.fuel.2011.12.039

Yao, Y. B., Liu, D. M., Che, Y., Tang, D. Z., Tang, S. H., and Huang, W. H. (2010). Petrophysical characterization of coals by low-field nuclear magnetic resonance (NMR). Fuel 89, 1371-1380. doi: 10.1016/j.fuel.2009.11.005

Yu, J., Armstrong, R. T., Ramandi, H. L., and Mostaghimi, P. (2016). Coal cleat reconstruction using micro-computed tomography imaging. Fuel 181, 286-299. doi: 10.1016/j.fuel.2016.04.127

Yu, Z., Zhang, L., Jiang, P., Papelis, C., and Li, Y. (2015). Study on waterrock interactions of traceelements in groundwater with leaching experiments. Groundwater 53, 95-102. doi: 10.1111/gwat.12182

Zhang, J., Peng, W., Liu, F., Zhang, H. X., and Li, Z. J. (2016). Monitoring rock failure processes using the Hilbert-Huang transform of acoustic emission signals. Rock Mech. Rock Eng. 49, 427-442. doi: 10.1007/s00603-015-0 755-5

Zhang, Y., Xu, X. M., Lebedev, M., Sarmadivaleh, M., Barifcani, A., and Iglauer, S. (2016). Multi-scale X-ray computed tomography analysis of coal microstructure and permeability changes as a function of effective stress. Int. J. Coal Geol. 165, 149-156. doi: 10.1016/j.coal.2016.08.016

Zhao, J. L., Xu, H., Tang, D. Z., Mathews, J. P., Li, S., and Tao, S. (2016). Coal seam porosity and fracture heterogeneity of macrolithotypes in the Hancheng Block, eastern margin, Ordos Basin, China. Int. J. Coal Geol. 159, 18-29. doi: 10.1016/j.coal.2016.03.019

Zhao, Y. L., Zhang, L. Y., Wang, W. J., Pu, C. Z., Wan, W., and Tang, J. Z. (2016). Cracking and stress-strain behavior of rock-like material containing two flaws under uniaxial compression. Rock Mech. Rock Eng. 49, 2665-2687. doi: 10.1007/s00603-016-0932-1

Zhao, Y. X., Sun, Y. F., Liu, S. M., Wang, K., and Jiang, Y. D. (2016). Pore structure characterization of coal by NMR cryoporometry. Fuel 190, 359-369. doi: 10.1016/j.fuel.2016.10.121

Zhao, Y. L., Wang, Y. X., and Tang, L. M. (2019). The compressive-shear fracture strength of rock containing water based on Druker-Prager failure criterion. Arab. J. Geosci. 12:452.

Zhao, Y. L., Zhang, L. Y., Wang, W. J., Wan, W., and Ma, W. H. (2018). Separation of elastoviscoplastic strains of rock and a nonlinear creep model. Int. J. Geomech. 18:04017129. doi: 10.1061/(asce)gm.1943-5622.000 1033

Zou, J., and Li, S. (2015). Theoretical solution for displacement and stress in strainsoftening surrounding rock under hydraulic-mechanical coupling. Sci. China Technol. Sci. 58, 1401-1413. doi: 10.1007/s11431-015-5885-1

Conflict of Interest: The authors declare that the research was conducted in the absence of any commercial or financial relationships that could be construed as a potential conflict of interest.

Copyright (C) 2020 Yao, Zheng, Tang, Xu, Chong and Li. This is an open-access article distributed under the terms of the Creative Commons Attribution License (CC BY). The use, distribution or reproduction in other forums is permitted, provided the original author(s) and the copyright owner(s) are credited and that the original publication in this journal is cited, in accordance with accepted academic practice. No use, distribution or reproduction is permitted which does not comply with these terms. 